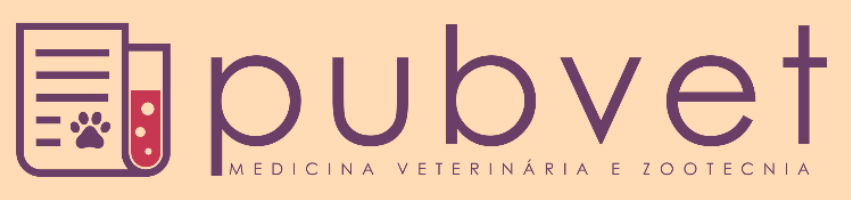

https://doi.org/10.31533/pubvet.v13n01a236.1-5

\title{
Caso sugestivo de hemoplasmose aguda em ratão-do-banhado (Myocastor coypus): Relato de caso
}

\author{
Sergiane Baes Pereira*1๑, Larissa Caló Zitelli² ${ }^{\ominus}$, Paulo Quadros de Menezes $^{3} \bullet$, Valéria \\ Defavari Moretti $^{30}$, Paulo Mota Bandarra ${ }^{50}$, Ana Raquel Mano Meinerz ${ }^{6}$ \\ ${ }^{I}$ Médica Veterinária pós-graduanda, Universidade Federal de Pelotas, Laboratório de Patologia Clínica Veterinária-Pelotas, RS, Brasil. \\ ${ }^{2}$ Médica Veterinária mestranda, bolsista da CAPES, Instituto de Pesquisas Veterinárias Desidério Finamor-Eldorado do Sul, RS, Brasil \\ ${ }^{3}$ Médico (a) Veterinário(a) Pós-graduando, Universidade Federal de Pelotas, Instituto de Biologia, Núcleo de Reabilitação da \\ Fauna Silvestre e Centro de Triagem de Animais Silvestres - Pelotas, RS, Brasil \\ ${ }^{4}$ Núcleo de Reabilitação da Fauna Silvestre e Centro de Triagem de Animais Silvestres - Pelotas, RS, Brasil \\ ${ }^{5}$ Médico Veterinário, Universidade Federal de Pelotas, Instituto de Biologia, Núcleo de Reabilitação da Fauna Silvestre e \\ Centro de Triagem de Animais Silvestres - Pelotas, RS, Brasil \\ ${ }^{6} \mathrm{Dr}^{a}$. Prof ${ }^{a}$., Universidade Federal de Pelotas, Departamento de Clínicas Veterinárias - Pelotas, RS, Brasil \\ *Autor para correspondência: sergiiane@hotmail.com
}

RESUMO. O presente trabalho tem como objetivo relatar um caso sugestivo de infecção por Mycoplasma spp. em ratão-do-banhado no município de Pelotas, Rio Grande do Sul, Brasil, atendido no Núcleo de Reabilitação da Fauna Silvestre e Centro de Triagem de Animais Silvestres da Universidade Federal de Pelotas (NURFS/CETAS - UFPel). Foi encaminhado ao NURFS/CETAS - UFPel um ratão-do-banhado (Myocastor coypus), macho, adulto, com peso aproximado de $4,8 \mathrm{~kg}$, resgatado na Praia do Laranjal, município de Pelotas, Rio Grande do Sul, Brasil. Durante o atendimento clínico do animal foi observado que o mesmo apresentava incoordenação motora e prostração, além de dificuldade de ingestão alimentar. Foram coletadas amostras sanguíneas do animal, acondicionadas em tubo contendo anticoagulante ácido etilenodiamino tetra-acético (EDTA), para a realização de hemograma. O hemograma foi realizado através de contagem celular, utilizando automação veterinária pocH-100iV Diff - Sysmex®; avaliação de esfregaço sanguíneo, previamente corado com Panotico Rápido®, através de microscopia óptica; e mensuração de proteínas plasmáticas totais (PPT) e fibrinogênio plasmático através de refratometria. Através da contagem celular e mensuração de PPT e fibrinogênio plasmático foi possível observar que o animal apresentava anemia, leucocitose e uma possível hiperfibrinogenemia. Na observação do esfregaço sanguíneo foram observadas estruturas basofílicas extracelulares ligadas à membrana das hemácias, compatíveis com a descrição morfológica de Mycoplasma spp., sugerindo um quadro de hemoplasmose aguda. Diante do quadro clínico, foi instituída antibioticoterapia com enrofloxacina 2,5\% (7 $\mathrm{mg} / \mathrm{kg}$ ). Após 15 dias de protocolo terapêutico foi possível observar melhora clínica e dos parâmetros eritrocitários do animal, sugerindo que o sucesso do protocolo terapêutico corrobora com o provável quadro infeccioso.

Palavras chave: hematologia, hemoplasmas, roedores, silvestres

\section{Case suggestive of acute hemoplasmosis in nutria (Myocastor coypus): Case report}

ABSTRACT. The present study aims to report a case suggestive of Mycoplasma spp. in a nutria, in Pelotas, Rio Grande do Sul State, Brazil, treated at the Center for Wildlife Rehabilitation and Center and Screening of Wild Animals, Federal University of Pelotas 
(NURFS / CETAS - UFPel), an adult and male nutria, about $4.8 \mathrm{~kg}$, was rescued at Praia do Laranjal, in the municipality of Pelotas, Rio Grande do Sul, Brazil. During the clinical care of the animal, it was observed that it had motor incoordination and prostration, besides difficulty in food intake. Blood samples were collected from the animal, packed in a tube containing anticoagulant ethylenediamine tetraacetic acid (EDTA), to perform blood counts. The hemogram was performed by cellular counting, using veterinary automation pocH-100iV Diff - Sysmex ®; evaluation of blood smear, previously stained with Panotico Rápido®, by light microscopy; and measurement of total plasma proteins and plasma fibrinogen through refractometry. Through cell counting and measurement of total plasma proteins and plasma fibrinogen, it was possible to observe that the animal had anemia, leukocytosis and a possible hyperfibrinogenemia. Blood smear observation showed extracellular basophilic structures attached to the red blood cells, compatible with the morphological description of Mycoplasma spp., suggesting acute hemoplasmosis. In the clinical setting, antibiotic therapy with $2.5 \%$ enrofloxacin $(7 \mathrm{mg} / \mathrm{kg})$ was instituted. After 15 days of therapeutic protocol, it was possible to observe clinical improvement and erythrocyte parameters of the animal, suggesting that the success of the therapeutic protocol corroborates with the suggestive infectious disease.

Keywords: hematology, hemoplasms, rodents, wild

\section{Caso sugestivo de hemoplasmosis en coipo (Myocastor coypus): Reporte de un caso}

RESUMEN. El presente trabajo tiene como objetivo relatar un caso sugestivo de infección por Mycoplasma spp., en coipo en el municipio de Pelotas, Rio Grande do Sul, Brasil, atendido en el Núcleo de Rehabilitación de la Fauna Silvestre y Centro de Triaje de Animales Silvestres de la Universidad Federal de Pelotas (NURFS / CETAS - UFPel). Fue encaminado al NURFS/CETAS-UFPel un coipo (Myocastor coypus), macho, adulto, con un peso aproximado de $4,8 \mathrm{~kg}$, rescatado en la Playa de Laranjal, municipio de Pelotas, Rio Grande do Sul, Brasil. Durante el atendimiento clínico fue observado que el del animal presentaba incoordinación motora y postración, además de dificultad de ingestión alimentaria. Se recogieron muestras sanguíneas del animal, acondicionadas en un tubo que contenía anticoagulante EDTA (ácido etilenodiamino tetra-acético), para la realización del hemograma. El hemograma fue realizado a través de conteo celular, utilizando la automatización veterinaria pocH-100iV Diff - Sysmex®; evaluación de frotis sanguíneo, previamente coloreado con Panotico Rápido ${ }^{\circledR}$, a través de microscopia óptica; y la medición de las proteínas plasmáticas totales (PPT) y el fibrinógeno plasmático a través de la refractometría. A través del conteo celular y la medición de PPT y fibrinógeno plasmático fue posible observar que el animal presentaba anemia, leucocitosis y una posible hiperfibrinogenemia. En la observación del frotis sanguíneo se observaron estructuras basofílicas extracelulares ligadas a la membrana de los hematíes, compatibles con la descripción morfológica de Mycoplasma spp., sugiriendo un cuadro de hemoplasmosis aguda. Ante el cuadro clínico, se instituyó antibioticoterapia con enrofloxacino 2,5\% (7 mg / kg). Después de 15 días de protocolo terapéutico, fue posible observar mejoría clínica y de los parámetros eritrocitarios del animal, sugiriendo que el éxito del protocolo terapéutico corrobora con el probable cuadro infeccioso.

Palabras clave: hematologia, hemoplasmas, roedores, salvaje

\section{Introdução}

Os hemoplasmas são bactérias eritrocitárias obrigatórias pertencentes ao gênero Mycoplasma spp. (Cubas et al., 2014). Esses microrganismos são caracterizados como bactérias pequenas, pleomórficas, não cultiváveis que se ligam à superfície dos eritrócitos e infectam uma ampla gama de animais selvagens, domésticos, além de seres humanos (Biondo et al., 2009; Vieira et al., 2009). Sua transmissão frequentemente envolve vetores artrópodes que se alimentam de sangue, 
parecendo haver uma elevada prevalência em regiões tropicais provavelmente devido à presença de condições que favorecem a transmissão desses microrganismos pelo vetor (Neimark et al., 2001; Biondo et al., 2009).

Durante os últimos anos pode-se observar um interesse crescente na infecção por hemoplasmas em animais domésticos e selvagens no Brasil, uma vez que o papel dos animais selvagens como reservatórios desses agentes para animais domésticos e vice-versa ainda é desconhecido (Biondo et al., 2009; Cubas et al., 2014). Dentre os animais selvagens, podem-se destacar os roedores, já que a maioria das espécies pode atingir grandes números de indivíduos em uma ampla gama de habitats, evidenciando seu significado epidemiológico como reservatório e hospedeiros de patógenos (Hornok et al., 2015).

O ratão-do-banhado (Myocastor coypus), também conhecido como nutria, é um roedor de habitat aquático, pertencente à família Capromyidae (Campos et al., 2010). Nativos do sul da América do Sul encontram-se disseminados em outras partes do mundo, como Europa e Estados Unidos, e habitam pântanos, margens de lagos e rios, especialmente onde há vegetação em abundância (Guichón et al., 2003). Embora existam relatos de infecção por hemoplasmas em roedores (Cubas et al., 2014), não foram encontradas na literatura informações acerca da infecção nessa espécie.

Sendo assim, o presente trabalho tem como objetivo relatar um caso sugestivo de infecção por Mycoplasma spp. em ratão-do-banhado no município de Pelotas, Rio Grande do Sul, Brasil, atendido no Núcleo de Reabilitação da Fauna Silvestre e Centro de Triagem de Animais Silvestres da Universidade Federal de Pelotas (NURFS/CETAS - UFPel).

\section{Relato do caso clínico}

Foi encaminhado ao NURFS/CETAS - UFPel um ratão do banhado, macho, adulto, com peso aproximado de 4,8 kg, resgatado na Praia do Laranjal, município de Pelotas, Rio Grande do Sul, Brasil.

Durante o atendimento clínico do animal foi observado que o mesmo apresentava descoordenação motora e prostração, além de dificuldade de ingestão alimentar. Previamente ao exame clínico foi realizado sedação, utilizando como protocolo cetamina $(7 \mathrm{mg} / \mathrm{kg})$, midazolan $(0,3 \mathrm{mg} / \mathrm{kg})$ e tramadol $(1 \mathrm{mg} / \mathrm{kg})$, afim de realizar-se avaliação clínica de forma adequada. No exame clínico foram avaliados os parâmetros vitais do espécime além de realizados testes neurológicos, que resultaram dentro dos padrões fisiológicos para a espécie avaliada. Durante o exame clínico a única alteração observada foi discreta palidez de mucosas.

Para a adequada condução do paciente foram coletadas amostras sanguíneas por punção das veias jugular e femoral. As amostras acondicionadas em tubo contendo anticoagulante ácido etilenodiamino tetra-acético (EDTA) para realização de hemograma. A amostra sanguínea foi processada no Laboratório de Patologia Clínica Veterinária da Universidade Federal de Pelotas (LPCVet - UFPel) imediatamente após a coleta.

A contagem celular foi realizada utilizando automação veterinária pocH-100iV DiffSysmex ${ }^{\circledR}$, que forneceu número total de hemácias, teor de hemoglobina, hematócrito, volume corpuscular médio (VCM), concentração de hemoglobina corpuscular média (CHCM), contagem plaquetária e contagem de leucócitos totais. A análise da morfologia celular e contagem diferencial de leucócitos foi realizada por avaliação por microscopia óptica de esfregaço sanguíneo previamente corado com corante Panótico Rápido ${ }^{\circledR}$, conforme descrito por Thrall (2015). Também, foi realizada mensuração da concentração de proteínas plasmáticas totais (PPT) e mensuração do teor plasmático de fibrinogênio, ambos por refratometria, conforme técnica descrita por Thrall (2015).

Ao realizar-se o hemograma foi observado que o animal apresentava $3,80 \times 10^{6}$ hemácias; $11,1 \mathrm{~g} / \mathrm{dl}$ teor de hemoglobina, hematócrito $36,0 \%$, VCM 94,7 fl e CHCM 30,8\%; 737x10 $10^{3}$ plaquetas; e 20.000 leucócitos totais/ $\mu$. Também foi observada concentração de $6,2 \mathrm{~g} / \mathrm{dl}$ de PPT e 500 $\mathrm{mg} / \mathrm{dl}$ de fibrinogênio plasmático. Na avaliação microscópica do esfregaço sanguíneo, para contagem diferencial de leucócitos, foram observados 17.000 neutrófilos/ $\mu 1, \quad 200$

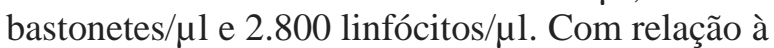
morfologia celular, durante avaliação do esfregaço sanguíneo, foram observadas irregularidades nas bordas das hemácias. Foi utilizada, então, objetiva de imersão (100X) para avaliação dessas hemácias. Neste momento foram observadas estruturas basofílicas extracelulares ligadas à membrana das hemácias, conforme demonstradas na figura 1, compatíveis com a descrição morfológica de Mycoplasma spp. 


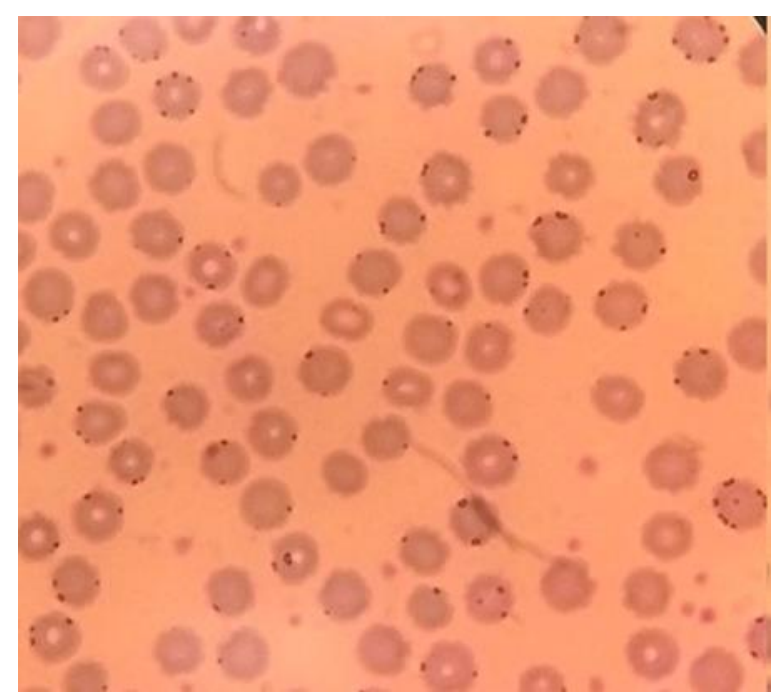

Figura 1. Esfregaço sanguíneo de Myocastor coypus, corado com Panótico Rápido ${ }^{\circledR}$, análise microscópica em objetiva de imersão:estruturas extra-citoplamáticas em hemácias compatíveis com Mycoplasma spp.

Foi instituída antibiótico terapia com enrofloxacina $2,5 \% \quad(7 \mathrm{mg} / \mathrm{kg})$, conforme recomendado por Cubas et al., (2014), durante 15 dias. Ao final do tratamento foi observado que o animal não apresentava os sinais clínicos previamente descritos. Foi realizado novo hemograma, no qual se pode observar elevação dos níveis eritrocitários $\left(4,33 \times 10^{6}\right.$ hemácias, 12,5 $\mathrm{g} / \mathrm{dl}$ teor de hemoglobina e hematócrito $40,7 \%$ ), diminuição do teor de fibrinogênio plasmático $(200 \mathrm{mg} / \mathrm{dl})$ e diminuição da contagem total de

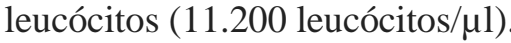

\section{Discussão}

Os resultados observados no hemograma demonstraram um quadro anêmico, já que os valores encontraram-se abaixo da média relatada para a espécie $\left(4,48 \times 10^{6}\right.$ hemácias; $14,1 \mathrm{~g} / \mathrm{dl}$; hematócrito 40,4\%) e leucocitose, uma vez que os valores de leucócitos totais encontraram-se acima da média relatada para a espécie (10.621

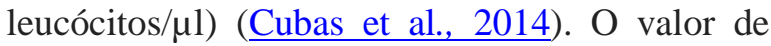
fibrinogênio, embora não tenha sido encontrado na literatura valores de referência para a espécie, foi superior ao relatado para a espécie Hydrochaeris hydrochaeris $(240 \mathrm{mg} / \mathrm{dl})$, roedor semi-aquático, também conhecido como capivara (Cubas et al., 2014), sugerindo um possível quadro de hiperfibrinogenemia.

Conforme Biondo et al., (2009), animais infectados, na forma aguda, podem apresentar anemia hemolítica leve a fatal em adição à anorexia, febre, icterícia e hipoglicemia, enquanto que Cubas et al., (2014) informaram que capivaras brasileiras infectadas com hemoplasma não apresentaram anemia e/ou sinais clínicos da infecção, assim como ratos e camundongos infectados com $M$. haemomuris normalmente não apresentam alterações clínicas e o hematócrito desses animais retorna ao normal de 3 a 6 dias depois do pico inicial. No animal do presente relato foi possível observar anemia, discreta palidez de mucosas e dificuldade alimentar.

Neimark et al., (2002) ressaltaram que na fase aguda de parasitemia, $100 \%$ dos eritrócitos podem ser infectados e um grande número de organismos, da ordem de 10-20, pode ser visto em eritrócitos individuais, conforme observado durante análise do esfregaço sanguíneo deste relato. Esse fato vai ao encontro da leucocitose e hiperfibrinogenemia também observadas, sugerindo o possível caráter agudo da enfermidade no momento da primeira análise hematológica, uma vez que a leucocitose está comumente relacionada a processos infecciosos e que o fibrinogênio plasmático é também chamado de proteína de fase aguda por ter sua concentração no sangue aumentada rapidamente em resposta a processos inflamatórios agudos (Gonzalez \& Silva 2006; Thrall 2015).

Não foi realizada técnica de reação em cadeia da polimerase (PCR) para identificação do agente infeccioso. Entretanto, a morfologia compatível com agentes do gênero Mycoplasma spp.; a melhora dos parâmetros hematológicos e clínicos e o desaparecimento das estruturas extrecelulares nas hemácias, demonstraram a eficácia do tratamento instituído, considerado de eleição para quadros de hemoplasmose. Esses fatos corroboram com a definição do possível processo infeccioso.

Vale ressaltar que a ausência de sinais clínicos e baixo número de micoplasmas na circulação, dificilmente observados em esfregaço sanguíneos, também são comumente associados à forma crônica da enfermidade, sendo que $s$ consequências da infecção em longo prazo ainda não estão claras (Biondo et al., 2009; Cubas et al., 2014). Os animais parasitados tornam-se portadores crônicos, apresentam-se frequentemente assintomáticos e, de maneira geral, são considerados portadores sãos, mas podem desenvolver a doença aguda em casos de eventos imunossupressores, tais como doenças concomitantes, utilização de corticoides e estresse (Biondo et al., 2009). Este fato não permite definir se o quadro deu-se em virtude de primo-infecção 
ou reagudização da enfermidade devido a algum evento imunossupressor.

$\mathrm{O}$ animal permaneceu no NURFS/CETASUFPel após o término do tratamento para adequado monitoramento e, posteriormente, encaminhado para o mesmo local no qual havia sido resgatado. Conforme Cubas et al., (2014) o papel dos animais silvestres como reservatórios desses agentes para animais domésticos e viceversa ainda é desconhecido. Também foi ressaltado por Neimark et al., (2001) que a maioria dos organismos provavelmente habitaria um único hospedeiro, porém o intervalo de hospedeiros da maioria das espécies não foi totalmente examinado, podendo ser necessário rever a ideia de hospedeiro específico. Tais informações demonstram a necessidade de um adequado monitoramento desses animais portadores, além do desenvolvimento de pesquisas para determinação do seu papel na cadeia de transmissão dos patógenos.

\section{Conclusão}

Em vista do exposto, pode-se concluir que foram observadas estruturas extracelulares sugestivas de Mycoplasma spp., indicativas de quadro agudo de hemoplasmose, em hemácias de um ratão-do-banhado atendido no NURFS/CETAS-UFPel.

\section{Referências bibliográficas}

Biondo A.W., Santos A.P., Guimarães A.M.S., Vieira R.F.d.C., Vidotto O., Macieira D.d.B., Almosny N.R.P., Molento M.B., Timenetsky J. \& Morais H.A. 2009. A review of the occurrence of hemoplasmas (hemotrophic mycoplasmas) in Brazil. Revista Brasileira de Parasitologia Veterinária 18, 1-7.

Campos R., Araújo A.C.P. \& Azambuja R.C. 2010. Ramos colaterais do arco aórtico e suas principais ramificações em nutria (Myocastor coypus). Acta Scientiae Veterinariae 38, 139146.

Cubas Z.S., Silva J.C.R. \& Dias J.L.C. 2014. Tratado de animais selvagens-medicina veterinária. Editora Roca.

Gonzalez F.H.D. \& Silva S.C. 2006. Introdução à bioquímica clínica animal. Gráfica de
Universidade Federal do Rio Grande do Sul, Porto Alegre, Rio Grade do Sul.

Guichón M.L., Doncaster C.P. \& Cassini M.H. 2003. Population structure of coypus (Myocastor coypus) in their region of origin and comparison with introduced populations. Journal of Zoology 261, 265-272.

Hornok S., Estók P., Kováts D., Flaisz B., Takács N., Szőke K., Krawczyk A., Kontschán J., Gyuranecz M. \& Fedák A. 2015. Screening of bat faeces for arthropod-borne apicomplexan protozoa: Babesia canis and Besnoitia besnoiti-like sequences from Chiroptera. Parasites \& Vectors 8, 2-6.

Neimark H., Barnaud A., Gounon P., Michel J.-C. \& Contamin H. 2002. The putative haemobartonella that influences Plasmodium falciparum parasitaemia in squirrel monkeys is a haemotrophic mycoplasma. Microbes and Infection 4, 693-698.

Neimark H., Johansson K.-E., Rikihisa Y. \& Tully J.G. 2001. Proposal to transfer some members of the genera Haemobartonella and Eperythrozoon to the genus Mycoplasma with descriptions of Candidatus 'Mycoplasma haemofelis','Candidatus Mycoplasma haemomuris','Candidatus Mycoplasma haemosuis' and 'Candidatus Mycoplasma wenyonii'. International Journal of Systematic and Evolutionary Microbiology 51, 891-899.

Thrall M.A. 2015. Hematologia e Bioquímica Clínica Veterinária. Editora Roca, São Paulo, Brasil.

Vieira R.F.C., Molento M.B., Santos L.C., Moraes W., Cubas Z.S., Santos A.P., Guimaraes A.M.S., Mohamed A., Barros Filho I.R. \& Biondo A.W. 2009. Detection of a novel hemoplasma based on 16S rRNA gene DNA in captive and free-ranging capybaras (Hydrochaeris hydrochaeris). Veterinary Microbiology 139, 410-413.

Recebido: 11 novembro, 2018.

Aprovado: 12 dezembro, 2018.

Publicado: 27 dezembro, 2018.

Licenciamento: Este artigo é publicado na modalidade Acesso Aberto sob a licença Creative Commons Atribuição 4.0 (CC-BY 4.0), a qual permite uso irrestrito, distribuição, reprodução em qualquer meio, desde que o autor e a fonte sejam devidamente creditados. 